\title{
Cross-Cultural Communication for Business in Era of Globalization
}

\author{
Maurice Odine \\ Correspondence: Maurice Odine, School of Communication, Texas Southern University, Houston, Texas, USA.
}

Received: March 12, 2018

doi:10.11114/smc.v6i1.3298

\author{
Accepted: April 7, 2018 \\ Online Published: May 25, 2018 \\ URL: https://doi.org/10.11114/smc.v6i1.3298
}

\begin{abstract}
The paper addresses the foundation of cross-cultural communication and its relation to global business. Shina Neo (2015) states that, humans take for granted their communication with one another, stating, "In a multicultural organization, how employees communicate can set the tone." Populations in North Africa and the Middle East believe in "external control" over destiny, meaning events are predetermined. In Japan, the productivity movement is based on respect for humanity, which is focused on cooperation. John-ren Chen and Christian Smekal (2004) argue that liberalizing international markets creates foreign capital and foreign investment. Concurring in support of global business are the European Union and African Union, Organization of American States and Caribbean Basin, plus the International Monetary Fund and World Bank. Furthering cross-cultural communication and global business is new information technology. Meanwhile, the latter has dismantled territorial boundaries. Nilüfer Karacasulu (2007) in, "Security and Globalization in the Context of International Terrorism," admits globalization is a challenge facing governments since the 1980s. Sougar, Grainger, and Hedges (1999) affirm culture is an interaction of values, attitudes and behaviors.
\end{abstract}

Keywords: cross-cultural communication, culture, business, globalization, cooperation

\section{Introduction}

With globalization come advantages and disadvantages, particularly in reference to international trade. This includes cross-cultural communication and education leading to $21^{\text {st }}$ Century's challenges in business research aimed at benefiting the global community and mankind. It behooves the global business community to create a synergy with cross-cultural communication. Tannen (1984) could not have been clearer. In the article "The Pragmatics of Cross-Cultural Communication," the author raises the difference in intonation. The writer refers to an experience at London's (United Kingdom) Heathrow Airport and narrated by Gumperz (1982). An airport employee who in the staff cafeteria complained about rudeness by cafeteria employees from India and Pakistan. They had been hired and placed in positions that are traditionally held by British women; the Asian women complained of discrimination. Gumperz audio-taped the cross-cultural communication and had Asian and British employees listen to it.

Hence, "Gravy," with a question intonation, means, "Would you like gravy." The same word, spoken with a falling intonation, means, "This is gravy. Take it or leave it." Consequentially, intonation can throw off cross-cultural communication without the communicators knowing the cause of the miscommunication. In essence, intonation is comprised of utterance, namely, degrees and shifts in pitch, loudness and rhythm. "Whereas speakers of British English use loudness only when they are angry, speakers of Indian English use it to get attention," confirms Tannen. British English speakers use loudness to express anger; an Indian speaker's loud voice is simply to get attention.

Yet, communicating with people from different cultures remains a constant challenge. In the blog on October 6, 2015, Shina Neo asserts that we take for granted the way we communicate with one another. Similar to everything else, says Shina, we make interpretations, create assumptions and form decisions based on our cultural upbringing. "In a multicultural organization, how employees communicate can set the tone and foundation for a learning culture," she continues. The writer believes it is critical to promote a work environment that supports business and customer needs, while instilling high standards of unity and worthy employee morale. Similarly, a productive international business creates a work environment which supports diversity, while balancing pressures of management, time and cost.

Shina emphasizes that, the key to success in international business is to accept the differences on a multicultural team and using them to build divers and cohesive teams. The opposite is being unaware of our own biases and placing stereotypes and cultural assumptions on others. Thus, creating organizational awareness through diversity training ensures that, employees learn to be culturally mindful, and are able to communicate with people of different 
backgrounds. In the modern age of global business, it is essential to develop and maintain effective cross-cultural communication. Mary Hunter (1993) stresses that managers must become proficient cross-cultural communicators if they are to succeed in today's global environment. In this regard, managers need to synthesize multiple insights from disciplines as diverse anthropology, psychology, communication, linguistics and organizational behavior. In turn, managers are to apply these disciplines to managerial communication. By definition, "culture consists of the values, attitudes and behavior in a given group of most of the people most of the time."

Contextually, "managerial communication" is to achieve a desired result: writing a memo, interviewing an applicant, running a meeting and preparing a presentation. To communicate effectively in any culture, managers should consider the following:

- Setting communication objectives;

- Choosing a communication style;

- Assessing and enhancing credibility;

- Selecting and motivating audiences;

- Setting a message strategy; and

- Using appropriate nonverbal behaviors.

In setting cross-cultural communication objectives, the managers should delineate the desired result, such as, signing a contract, to provide information or approve recommendations or come up with a solution. In the context of cross-cultural communication, and from a global perspective, the manager is to consider the communication objective. This can be attained by asking two questions.

First, "Is my objective realistic, given the culture?" A realistic goal in one culture may not be the same in another culture. One way to gauge is to analyze what phycologists call the "locus of control." People in certain cultures tend to believe in "internal controls" over destiny by which humans can control events themselves. People in other cultures, including North Africa and Middle East, believe in "external controls" over destiny. Here, events are predetermined and uncontrollable. Where an American manager sets a goal to "construct the new building on schedule," a Muslim might consider as irreligious, because Muslims believe that human efforts are determined by the will of Allah, and not by a schedule. On the other hand, non-Muslims may have to adjust their expectations accordingly.

Muslims are not alone when it comes to believing in external control over events. Filipinos, though predominately Christian, tend to be fatalistic. A well-known saying in Tagalog is, "babala na," or "God wills it." Filipinos may view the manager's communication objective as predetermined by fate, rather than as controllable by individual effort. Second, the manager must ask, "Is my time frame realistic, given the culture?" The question is relevant, since what constitutes an appropriate time frame in one culture may not be achievable in another. It depends on the culture's concept of time. In some cultures, timetables are exact and precise, hence one can expect to start meetings on time and setting deadlines for tasks. Examples of such cultures include Germany, United States and Switzerland. However, in the African examples of Cameroon, Nigeria, and Morocco, timetables are more or less based on convenience.

No one is independent. In fact, human or national attempts to become independent come with grave limitations. For instance, being independent cannot even provide one's basic needs, let alone those needs that can only be furnished by others. Consider dealing with the following personal early morning essentials: toothpaste; shaver or razor; shower; bathtub; shampoo; conditioner; lotion or moisturizer; comb; or mirror. The fact is, some, or most of these items, are manufactured somewhere, most likely in another country, and made available to humans across the globe through international business facilitated by international cooperation. To highlight the point further, air travel is usually in the form of plane flights from different parts of the globe. The planes are flown by pilots who ask, and are granted permission, to fly over the air space of cooperating nations. The emerging picture is that, international cooperation is the foundation for international business, without which national business will wither in the face of shrinking markets for products or services. This underscores the invaluable mutuality of international cooperation and globalization on the one hand, and how this mutuality fuels international business on the other. But it behooves mankind to appreciate the evolution of cross-cultural communication and international business to which the world's 196 countries subscribe.

For instance, the Japan Productivity Center (JPC) has long been engaged in a host of international cooperation endeavors. JPC was established to transfer technology and know-how to improve productivity overseas. In the 1960s, a number of leaders of Asian countries began to show great interest in the miraculous recovery of Japan's postwar economy and its leadership in the productivity movement. In response to demands by the international community, the Japanese government established the Asian Productivity Organization (1962), charging it with the mission to systematically promote international cooperation. Not to be left out, countries outside Asia have since requested 
Japanese support. In October 2013, the Renault-Alliance and West African conglomerate, Stallion Group, signed a memorandum of understanding (MOU) to start a vehicle assembly in Nigeria as a major manufacturing hub for Africa. Plans are underway to launch Nissan's Datsun brand in South Africa in 2018.

International trade opens the eyes of governments looking for fiscal opportunities. Actually, governments would be devoid of any meaningful budgets without taxation; the yearning to cut a "pretty" slice out of tax revenue transcends national boundaries. John-ren Chen, and Christian Smekal, in the article, entitled, "International Tax Competition: A Case for International Cooperation in Globalization," argue that the liberalization of international financial flow has induced counties to use diverse measures to attract inflow of foreign capital and foreign direct investment. These steps, the authors emphasize, are expected to have a positive impact on the gross domestic product (GDP), hence a positive effect on the social welfare of nations.

The favorable outcome, though, is only possible when the tax rate of home countries is lower than that of foreign countries. It is at this crucial juncture that international tax cooperation (tax harmonization) can improve the welfare of participating countries. Nancy Buchman et al. refer to it as "Globalization and Human Cooperation." In the 2008 proceedings of the National Academy of Sciences, the researchers state that, globalization magnifies the problems that affect all people, adding that it requires human cooperation. The researchers state that, globalization is a powerful force for shaping large-scale cooperation in today's societies. Among subjects drawn from general populations of six countries in varying levels of globalization, results show tendencies essentially favor cooperation with globally remote others.

Knowledge cannot be taken for granted. So, just what is globalization? The Global Policy Forum articulates that, human societies have progressively established closer contacts over many centuries; the pace has dramatically increased. Why? The answer is not far-fetched: Jet airplanes, cheap telephone service, email, computers, iPads and tablets, smart-phones (such as iPhone X and Samsung Galaxy 9), huge ocean-going vessels and instant capital flow have all made the world more interdependent than ever. And since politics is all around us with wielding power to shape or dictate what happens around humans, globalization is being undertaken with national and political overtones. As a result, governments have become responsible for maintaining the security and economic welfare of their citizens, including protecting human rights and the environment territorial boundaries. In view of an ever integrated economy and other international trends, political activity increasingly occurs within the sphere of globalization. This tendency employs cross-cultural communication in conducting global business.

Thus, under globalization, politics can take place above the state, through political integration schemes, such as: the European Union; African Union; Organization of American State; Caribbean Basin; International Monetary Fund; World Bank; World Health Organization; Food and Agriculture Organization; and World Trade Organization. Political activity can also transcend national borders through global movements and nongovernmental organizations (NGOs). Civil society organizations act by forming alliances with organizations in other countries using global communications systems and lobbying international organizations and other actors. In effect, international cooperation and globalization produce tangible results to benefit even the peasant in the remote village of a developing country. Multinational corporations manufacture products in many countries and sell to consumers around the world. Accordingly, money, technology and raw materials move ever more swiftly across national borders. In the meantime, products, services, finances, ideas and cultures circulate more freely, establishing a climate whereby laws, economies, and social movements converge at the international level.

\section{Literature Review}

\subsection{National Challenges to Cross-Cultural Communication}

But globalization is not without shortcomings. Remarkably, technology has created the notion of a global culture. The Internet, fax machines, satellites, and radio and cable television networks, are dismantling cultural boundaries. Global entertainment companies shape the perceptions and dreams of ordinary citizens, wherever they live. In Kuwait, a 20-year old girl enrolled in my introduction to mass media class and wrote a term paper. In it, she said her younger sister, a fan of wrestling shown weekly on television, tried a move on her nine-year old sister, raising her up in the air, and dropping her to the floor, head first. The student lamented that her "baby" sister died.

Typically, a Kuwaiti millennial has at least, two smart phones: one iPhone and the other a Blackberry or Samsung. The phones are carried everywhere. The spread of values, norms, and culture tends to promote Western ideals of capitalism. Here are a few questions: Will local cultures continue to fall victim to global "consumer" culture? Will English eradicate all other languages? Will consumer values overwhelm peoples' sense of community and social solidarity? Or will a humane-friendly common culture embrace cross-cultural communication so global business may lead the way to global values and political unity? 
These questions summon the brains of mankind's best and brightest. As expressed by Eric Lee in the article, "Unconventional Solutions," and published in, Stanford Social Innovation Review (2012), development, environment, and innovative and unconventional solutions are urgently needed. But as new solutions to society's problems are explored, one has to be careful not to assume universal applicability because (as stated above) what works in one country or region may not work in another.

Why? The histories and cultures of countries are so different that, the paths they take are bound to differ. Lee points that today's social, economic and environmental problems require international cooperation in order to address different forms and cultures. But for billions of the world's people, business-driven globalization means uprooting traditional old ways of life which threaten livelihoods and cultures. The global social justice movement proposes an alternative path embedded with solutions that are more responsive to public needs. Accordingly, intense political disputes will be waged over globalization's meaning and its future direction. Auspiciously, these responsive solutions are debated in the annals of international cooperation and globalization.

\subsection{Partnerships of Cooperation and Globalization}

Nonetheless, globalization is not without shortcomings. International cooperation and globalization form an integral basis for international security, while simultaneously safeguarding the conduct of global business. Nilüfer Karacasulu, in writing, "Security and Globalization in the Context of International Terrorism," and published in the Journal of Turkish Weekly, acknowledges that, globalization is an encompassing challenge facing governments since the 1980s. Nilüfer Karacasulu declares that globalization dominates the study of international cooperation and globalization. "An international problem such as terrorism can only be defeated by international cooperation," said Elmar Brok, member of European Parliament. Sergey Ordzhoridze, UN Undersecretary and Director General, added, "Terrorism is a global threat that can never be justified. A new vision of global security is needed - one that must confront terrorism, respect human rights and draw upon international cooperation."

Lessons can be learned on international security given the lessons of September 11, 2001, in the US. Security threats of the day warrant an examination and regular assessment of cyber space exploitation. This prompted the International Conference on Cyber Security, jointly organized by the US Federal Bureau of Investigation (FBI) and Fordham University in New York on August 8, 2013. FBI director, Robert Mueller, reiterated that, cyber threat will "equal the terrorist threat," in light of the "proliferation of adversaries in the cyber arena." Mueller called on the international community to devise a response that is effective, not just against a specific attack.

Ongoing ventures include the National Cyber Investigative Joint Task Force, InfraGard, and the Domestic Security Alliance Council. "By fusing private-sector information with information from the intelligence community, we can produce a complete picture of cyber threats - one that benefits all of us," said Mueller.

In Europe, high representative Catherine Ashton has spearheaded a new Cyber Security Strategy through the European Commission (EU). It is the first comprehensive policy document that the EU has produced in this area. It consists of internal market, justice and home affairs and foreign policy matters of cyber space. The EU international cyber space community offers the following priorities:

- Freedom and openness, outlining the vision and principles on applying EU core values and fundamental rights in cyber space;

- The laws, norms and EU core values apply as much to cyber space as in the physical world; hence the responsibility for more secure cyber space lies with all players of the global information society, from citizens to governments;

- Developing cyber security capacity building, whereby the EU will engage with international partners and organizations, the private sector and civil society to support global capacity building in developing countries. It will include improving access to information to an open Internet, and preventing cyber threats; and

- Fostering international cooperation in cyber space issues, in a bid to preserve open, free and secure cyber space is a global challenge, in which the EU will work with the relevant international partners and organizations, as well as with private sector and civil society.

A prime prerequisite in fulfilling needs is safety and peace of mind. In the Summer 2009 issue of Vision: Insights and New Horizons, entitled, "From Globalization to Global Peace," the publication writes about humankind's desperate need for peace. It states, "One of most tantalizing and promising ways to achieve this age-old objective is to establish global governance. 


\subsection{Common Cross-Cultural Communication Challenges}

Peace is certainly an all-important staple in living and communicating with diversified populations from various cultural backgrounds. DuPraw and Axner write in Houston Pubic Media under the caption, "Working on Common Cross-Cultural Communication Challenges." The authors admit humans communicate with one another all the time, that is, in the home, workplace, within groups and in the community. "No matter how hard we think we understand each other, communication is hard," say the authors. Here is an example: "He doesn't get it," or "She didn't' really hear [understand] what I mean to say." Culture is inherently at the root of communication challenges. It influences how humans approach problems and how they participate in groups and communities. "Exploring the ways in which various groups within our society have related to each other is key to opening channels for cross-cultural communication," state DuPraw and Axner.

The authors present fundamental patterns of cultural differences. The first is different communication, as language. Across cultures, certain words and phrases are used in different ways. In English, the meaning of "yes" varies from "maybe, I'll consider it," to "definitely so." Obviously, there are shades of meaning. Some white Americans consider raised voices as a sign that a fight has begun, while to some black, Jewish and Italian Americans, an increase in volume is a sign of an exciting conversation among friends. The second is different attitudes toward conflict. Some cultures view conflict as positive, while others view it as something to be avoided.

In the US, conflict is not generally desirable; but people are often encouraged to deal directly with conflict, as in face-to-face communication. In Eastern countries, open conflict is seen as embarrassing or demeaning. The third fundamental pattern of cultural difference is approaches to completing tasks. Cultures differ regarding the importance placed on establishing relationships or collaboration when it comes to working together to accomplish a task. Asian and Hispanic cultures tend to attach more value to developing relationships at the beginning of a shared project and more emphasis on task completion toward the end.

\section{Method}

The paper set to investigate the interrelationships between cross-cultural communication and globalization in the era of globalization using qualitative descriptive/interpretive research methodology. Elliott and Timulak (2005), in "Descriptive and Interpretive Approaches to Quality Research," state that these research methods, which are used today, are a diverse set encompassing approaches such as empirical phenomenology, grounded theory, ethnography, protocol analysis and discourse analysis. According to Polkinghorne (1983), these methods rely on linguistic, rather than numerical data; they employ meaning-based, instead of statistical forms of analysis.

Research addressed a number of topics. The first topic assessed international cooperation with the context of globalization. The second topic addressed mass collaboration and changes as seen by participants or players in cross-cultural communication and globalization. Question three looked at the importance of cross-cultural communications in global business. Question four examined educational perspectives on cross-cultural communication in light of incorporating channels into global business. And question five surveyed prospects of educating tomorrow's leaders in the global market.

An attempt was made to produce a comprehensive document that can serve as resource for entrepreneurial adventures/initiatives, organizations or governments that seek to expand opportunities and/or desire a documented foundation in cross-cultural communication in the $21^{\text {st }}$ Century's global business environment. The document may also serve students and scholars in their quest to expand knowledge in the subject under investigation.

\section{Results}

\subsection{Assessing International Cooperation and Globalization}

Obviously, international cooperation and globalization come with advantages and disadvantages. These are a few:

- Industrial: emergence of world production markets and broader access to a range of foreign products for consumers and companies. This is particularly the case where movement of material and goods between, and within national boundaries, is concerned;

- Financial: emergence of worldwide financial markets and better access to external financial resources for borrowers. As these worldwide structures grow more quickly than any transnational regulatory regime, the instability of the global financial infrastructure dramatically increases. A case in point is the financial crisis of late 2008;

- Economic: realization of a global common market based on the freedom of exchange of goods and capital. The interconnectedness of these markets signals an economic collapse that a country cannot be sustain; 
- Political: "globalization" (creation of a world government) regulates relationships among governments and guarantees the rights emanating from socio-economic globalization. China is poised to have enough wealth, industry, and technology to rival the US as a leading world power;

- Competition: survival in the new global business market calls for improved productivity and increased competition. In a global market, companies must upgrade their products and use technology to be competitive;

- Ecological: global environmental challenges require international cooperation. This includes climate change, cross-boundary water and air pollution, over-fishing of the ocean and the spread of invasive species. Since many factories are built in developing countries with less environmental regulation, globalization and free trade may increase pollution. On the other hand, economic development requires a "primitive" industrial stage suited for developing countries to help raise their standard of living; and

- Cultural, that is, growth of cross-cultural contacts, advent of new categories of consciousness and identities which embodies cultural diffusion, the desire to increase one's standard of living and enjoy foreign products and ideas, adopt new technology and practices, and to participate in a "world culture." Some bemoan the resulting consumerism and diminishing loss of languages.

The international cooperation research initiative commenced in 1983 when the European Commission (EU) launched the Science and Technology for Development Program. In 1992, the program was integrated into the Research Framework Program. In 1995, a resolution, "communication on the strategic role of international cooperation for development," was articulated; and in 1997, the EU established the Research, External Relations, and Development Cooperation agency to strengthen the International Cooperation Program to interact with major regions of the world. In 2012 , the commission adopted a new strategy for implementing international cooperation measures.

It is evident the co-existence of cultures, either for reasons of survival or cooperation, is at the core of globalization. By the same token, globalization will cease to exist, or function efficaciously, in the absence of international training or cross-cultural experiential learning, respect and trust. But for nations and citizens to maximize their relationships with other world's humans (or to forge new ones), they must accept and recognize that globalization is not a homogenous culture. It epitomizes the ideal that, no one nation enjoys a monopoly on universal goodwill or mechanics of international cooperation.

\subsection{Mass Collaboration and Changes}

Today, the world may be approaching the reality of "worldwide cooperative governance." The impetus lies in the actuality that, connectedness across borderless cyberspace has become possible since the World Wide Web (WWW) tore down centralized structures. WWW has subsequently changed the way the world does business. These new developments prompted Don Tapscott and Anthony Williams to write the book, "Wi" [no relation to WikiLeaks!]. The authors assert that, people participate in the world economy like never before thanks technology. There is a new wave of collaboration in inventing, producing, marketing and distributing services and products on a global scale.

Likewise, Oro Brafman and Rod Beckstrom, in their book, The Starfish and the Spider: The Unstoppable Power of Leaderless Organizations, indicate that, decentralization has been lying dormant for thousands of years. The authors insinuate that, the advent of the Internet has unleashed this force, knocking down traditional businesses, altering entire industries, affecting how we relate to each other and influencing world politics. Ed Yong is a believer in international cooperation and globalization. Yong posted a blog, "Globalization increases cooperation at an international scale," on the Science Blogs, on March 2, 2009. The blogger maintains that 96 percent of the blog's readers make their homes in a different city; 91 percent live in another country. Yong is convinced the blog commands readers, which is indicative of globalization, writing, "Through telecommunication, the Internet, free trade, air travel and more, the world's population is becoming increasingly connected and dependent on one another."

\subsection{Importance of Cross-Cultural Business Communications}

Globalization is not without shortcomings. Contemporarily, global business calls for the ability to communicate effectively and multiculturalism cannot be underestimated. Gayle Cotton is a communications expert with particular interest in behavioral and cultural science and in managing multicultural clientele. "Over the years I have shared my experiences with entrepreneurs and businesses all over the world," says the writer. Gayle Cotton states cross-cultural factors that may adversely affect developing relationships with individuals or businesses from different cultural backgrounds. These are:

- Not being proactive and adapting to different cultural business expectations. It's all too easy to get off on the wrong foot and become reactive;

- Not understanding how formality, hierarchy and timing can affect business; 
- Being perceived as too aggressive or even impatient in your business approach.

- Business often takes longer with different cultures and countries, so plan accordingly; and

- Many cultures are more team-focused or "we" oriented. This can really impact your business style and marketing material. Also, avoid being egocentric or "I" oriented.

Five keys are essential in developing business partnerships, a) Be proactive. Start by focusing on creating trusting partnerships, b) Use some cultural rapport. Adapt your marketing material and business approach as needed, c) Organize productive interactions that ensure a "win-win" for all parties, d) Develop strategies for relationships and business cycles based on appropriate levels of formality, business hierarchy and timing, and, e) Learn the "do's and don'ts" of the country and culture you're working with.

Above all, a significant trio, namely, international cooperation, globalization and business, is a dominant force to in the 21 st Century. The trio is cognizant of respective limitations. As a result, it relies heavily on the resources of one another, because when a trio member falters, it adversely affects international cooperation and globalization, and ultimately global business. So, it is incumbent on the business community to perpetually conduct advanced research in order to maximize the positive effects of international cooperation and globalization on the one hand, and to minimize the negative effects on the other. Implicitly, cross-cultural communication is the glue that holds the together the trio.

\subsection{Educational Perspectives on Cross-Cultural Communication}

Global business and cross-cultural communication are a duo that largely depends on higher education to buttress growth and international partnerships. No sound argument can be made against the fact that, the Western world remains a cradle of post-secondary education for developing countries, particularly from Africa, Latin America, the Caribbean and the sub-Asian continent (India, Pakistan, Afghanistan). For international students, their stay in, say, the United States, comes with adjustment challenges. Morgan (1995) states that, when foreign students arrive in the US, they experience the phenomenon of "culture shock." The latter describes the initial stress and strain because they have moved to un unfamiliar habitat. "Living in a different culture influences your mental, emotional and physical sense of wellbeing," declares Morgan. Consciously or unconsciously, these international learners do not completely understand the customs and behavioral of another culture.

Thus, foreign students studying in the US face transitional experiences; they must choose how to deal with these experiences. And when they elect to modify their behavior and adapt to that of the host culture, each event serves not only as a lesson, but also an opportunity to learn new behavioral patterns. When they choose to adapt, the interactions sometimes form the basis for frustration, anger and sometimes helplessness. The author suggests the following considerations when transitioning into US culture:

- All learning involves change, and all living and educational experiences in the US provide opportunities for new learning;

- The feelings resulting from change can be thought-provoking, and persons experiencing culture shock can benefit from the analysis; and

- A person experiencing culture shock most often receives feedback from individuals and from the environment. They can learn from this feedback.

For international students and foreigners pursuing entrepreneurial initiatives in the US, there are five values that are recommended to enhance cross-cultural communication skills. First value is preferred topics. Americans talk casually with friends and engage in "small talk." Small talk subjects include the weather, sports, the latest movies, jobs and acquaintances. Politics are regarded as controversial topics that Americans tend to avoid, except during discussion with people one knows or trusts. Second value is verbal communication. American generally speak for short periods during conversation, engaging others to participate in the conversation. It is seen as impolite to dominate conversations, although confrontation is unavoidable. However, it is expressed more or less with restrain and controlled manner using a non-combative tone and voice. Third value is depth of involvement. Americans discuss topics with very close friends and, occasionally, someone they may never see again. Conversations are generally superficial. The fourth is preferred channels. The ideal American is to be verbally adept. Speaking in a moderate tone and avoiding use of hand or arm gestures. Physical touching during a conversation may include a touch on the arm or shoulder; not everyone may be comfortable with this expression. Indeed, women touch more often than men. A comfortable physical space between individuals is an arm's length, unless one is a close friend. And fifth value is nonverbal communication. When speaking to an individual, Americans look into the listener's eyes and then slightly look away. As for the listener, one will almost constantly make direct eye contact with the speaker. Generally, Americans distrust persons who do not look them in the eyes when talking to them. 


\subsection{Educating Tomorrow's Leaders on Culture \& Global Market}

Cross-cultural communication must be incorporated into higher education to train future researchers and international business leaders. Education is a sure way means to ensure present and future generations would not be devoid of this important global imperative. This is a bold and lofty endeavor that must be embraced by teachers; governments; public and private sectors; non-profit organizations; and individuals who yearn to make the world a better place. Educating tomorrow's leaders is emblematic of educators and managers who see themselves as custodians of global society's values amidst cultures. Sugar, Grainger, and Hedges (1999) refer to culture as an important idea that deals with the way people live and approach problem solving in social and organizational context, as well as collective programming of the mind which distinguishes members of one group or category from another. The authors hold the view that, values influence attitudes, and that attitudes affect behaviors. Sugar, Grainger, and Hedges claim behaviors have an impact on cultures. When people from two different cultures engage in exchanging messages, they do so through cross-cultural communication.

According to LeBaron (2003), examples of values, attitudes, and behaviors involve four variables. The first is time and space, the most central differences that separate cultures and cultural ways of doing things. For instance, Western rules for meetings enforce a non-chronic idea of time. Meanwhile, in the East, time has unlimited continuity resulting in a non-strict boundary. An intrinsic phenomenon of language in a given culture is the use of proverbs, which is an important tool in cultural understanding. The Moroccan proverb, "do not do today what you can do tomorrow," reflects the notion of time in Moroccan culture. Moroccans do not feel committed to their meetings and it is not embarrassing to come late. There is a joke about this attitude. Two Moroccans were planning to meet each other. One said, "We will fix it up at 8:00." The other answered, "Ok, if I don't come at 8:00, I will call you at 9:00 to say that I will not be able to come at 10:00. Hence, I will come at 11:00 to fix up another meeting." The third is face-to-face saving which includes ideas of status, power, courtesy, insider and outsider relations, humor and respect. The fourth variable is non-verbal communication, which implies that emotions of anger, fear, sadness, disgust, and surprise are expressed in similar ways around the world. In Cameroon, it is said, "A man's tears are in his heart."

As people become familiar with these variables, they are, in effect, engaged in cultivating reflections on ways in which cultures operate in communication and conflict, and to be able to respond effectively to these cultural differences. Dewey (1938) wrote about learning when he said, "It is to a large extent the cultural product of societies that assumed the future would be much like the past, and yet it is used as educational food in a society where change is the rule, not the exception." To be simplistic yet realistic, the world is not static; neither should ideologies about higher education in view of the global market which requires human capital, complex skills and knowledge. "The Policy on Internationalization" at a Swedish university articulates that, "Critical thinking, personal development and career preparation and respect for other peoples and cultures, and values remain a cardinal element of all education," and that intercultural education contributes to introspective appreciation of one's own culture. Teather (2004) does not quarrel with the assertion, while Rudzki (1995) lays down four dimensions: organizational change; curriculum innovation; faculty development; and student mobility.

\section{Conclusion}

It is evident international cooperation is alive and well, and that it is an integral to human existence and in conducting global business. Even basic livelihood cannot do without the virtues of cooperation, be it cooperation by a friend, family, or community. And when there is a pluralism of products and services for a multiplicity of humans across national boundaries, cross-cultural communication is the glue that holds together global business and international cooperation in the sphere of globalization.

In the blog on October 6, 2015, Shina Neo declares we take for granted communication with one another. Similar to everything else, says Shina, we make interpretations, create assumptions and form decisions based on our cultural upbringing. "In a multicultural organization, how employees communicate can set the tone and foundation for a learning culture," she continues. In the 2008 proceedings of the National Academy of Sciences, the researchers state that, globalization magnifies the problems that affect all people, adding that it requires human cooperation.

Under globalization, politics can take place above the state, through political integration schemes such as the European Union or African Union, Organization of American States, Caribbean Basin, and through intergovernmental organizations such as the International Monetary Fund, World Bank, World Health Organization, Food and Agriculture Organization, and World Trade Organization. Political activity can also transcend national borders through global movements and nongovernmental organizations (NGOs). As expressed by Eric Lee in, "Unconventional Solutions," and published in Stanford Social Innovation Review (2012), development and the environment are urgently needed. However, as new ideas and solutions to society's problems are explored, one has to be careful not to assume the universal applicability of these solutions because what works in one country might not work in another. According to 
Eric Lee, five keys are essential in developing business partnerships. These are, a) Be proactive. Start by focusing on creating trustful partnerships, b) Use some cultural rapport. Adapt your marketing material and business approach as needed, c) Organize productive interactions that ensure a "win-win" for all parties, d) Develop strategies for relationships and business cycles based on appropriate levels of formality, business hierarchy and timing, and, e) Learn the "do's and don'ts" of the country and cultures with which you're partnering.

The international cooperation research initiative commenced in 1983, when the European Commission launched the Science and Technology for Development Program. In 1992, the Program was integrated into the Research Framework Program; in a 1995 resolution, a "communication on the strategic role of international cooperation for development," was articulated; and in 1997, the EU established the Research, External Relations, and Development Cooperation agency, which strengthened the International Cooperation Program to engage in dialogue with major regions of the world. In 2012, the commission adopted a new strategy for implementing international cooperation measures.

Ed Yong posted a blog, "Globalization increases cooperation at an international scale," on the Science Blogs, on March 2, 2009. The blogger maintains that 96 percent of the blog's readers make their homes in a different city, while 91 percent live in another country. Yong is convinced that, since the blog commands readers are a reflect attitudes of globalization, stating, "Through telecommunication, the Internet, free trade, air travel and more, the world's population is becoming increasingly connected and dependent on one another." Morgan (1995) states that, when foreign students arrive in the United States (US), they experience the phenomenon of "culture shock." The latter describes the initial stress and strain due to experience having moved to un unfamiliar habitat. "Living in a different culture influences your mental, emotional and physical sense of wellbeing," declares Morgan.

Admittedly, cross-cultural communication is indispensable since the world is immersed in globalization. Also noteworthy is the fact that global business cannot thrive without the indispensable role played by cross-cultural communication in view of the varied cultural stripes in today's world. Important as well is recognition that, government and non-profit organizations, such as the European Union, African Union the United Nations, are continually providing "country-friendly" beneficial treaties and platforms designed to alight the world's nations to causes of common good. To be blunt, north versus south is no longer a winning proposition; nor is the boastful claim of the West defeating or obliterating the West, and vice versa. The international community (and humans therein) has no choice but to live within the confines of a technology-driven $21^{\text {st }}$ Century global society. The latter's agenda is to promote and sustain global business for the good of mankind. Henceforward, cross-cultural communication will continue to ease or eradicate cultural wars across vast lands and waters, replacing hostility with global prosperity, understanding and cooperation.

\section{References}

Axner, M., \& Dupraw, Marcelle E. Working on Common Cross-cultural Communication Challenges. http://www.pbs.org/ampu/crosscult.html

Brafman, O., \& Beckstrom, R. (2008). https://www.amazon.com/Starfish-Spider-Unstoppable-Leaderless-Organizations/dp/1591841836

Brok, Elmar is a member of European Parliament and current chairman of the European Parliament Committee on Foreign Affairs. He is president of the Union of European Federalists (since 2013).

Chen, J. R., \& Smekal, C. (2004). International Tax Competition: A Case for International Cooperation in Globalization. https://doi.org/10.1007/s11300-004-0005-0

Cotton, G. The Importance of Cross-Cultural Communication. https://www.eonetwork.org/octane-magazine/special-features/theimportanceofcross-culturalbusinesscommunications

Dewey, J. (1938). Experience and Education. New York: Simon \& Schuster. From Globalization to Global Peace, (author and date not provided) and published in Vision: Insights and New Horizons.

Dupraw, M. E., \& Axner, M. (undated). Working on Common Cross-cultural Communication Challenges Houston Public Media.

Gumperz, J. J. (1982). Discourse Strategies. Cambridge, UK: Cambridge University Press. https://doi.org/10.1017/CBO9780511611834

Hunter, M. (1993). Cross-Cultural Communication for Managers, Business Horizons, 36(3), 69-78. https://doi.org/10.1016/S0007-6813(05)80152-1

Japan Productivity Center. http://www.jpc-net.jp/eng/

Karacasulu, N. (2007). Security and Globalization in the Context of International Terrorism, Journal of Turkish Weekly, February 9. 
Lee, E. (2012). Unconventional Solutions, Stanford Social Innovation Review. https://ssir.org/articles/entry/unconventional_solutions

Morgan, R. T. (1995). Cross-Cultural Communications Impact Global Business, journal/publisher unnamed.

Nancy Buchman et al. (2009). Globalization and Human Cooperation, Proceedings of the National Academy of Sciences, DOI: 10.1073/pnas.080922106.

Nee, E. (2012). Unconventional Solutions, Stanford Social Innovation Review: Informing and inspiring leaders of social change.

Ordzhoridze, Sergey is UN under-secretary and director general.

Proceedings of the National Academy of Sciences (2008). www.pnas.org/content/by/year/2008

Rudzki, R. (1995). The application of a strategic management model to the internationalization of higher education institution. https://doi.org/10.1007/BF01383961

Sugar at al. (1999). Invisible kingdoms: the use of grave-goods in the seventh-century England. In The Oxford Handbook of Anglo-Saxon Archaeology. Oxford Press: UK.

Tannen (1984). The Pragmatics of Cross-Cultural Communication, Applied Linguistics, 5(3).

Tapscott, D., \& Williams, A. (2008). How mass collaboration changes everything, Journal of Communication, 2, 402-403.

Yong, E. (2009). Blog titled, Globalization increases cooperation at an international scale.

\section{Copyrights}

Copyright for this article is retained by the author(s), with first publication rights granted to the journal.

This is an open-access article distributed under the terms and conditions of the Creative Commons Attribution license which permits unrestricted use, distribution, and reproduction in any medium, provided the original work is properly cited. 